\title{
As competências desenvolvidas no ensino superior de contabilidade e sua importância para a profissão: 0 cenário português
}

\section{Skills developed in accounting in higher education and its importance for the profession: The Portuguese scenario}

\author{
Alexandra Margarida Domingos \\ Instituto Superior de Contabilidade e Administração de Lisboa, Portugal \\ amrodrigues@iscal.ipl.pt \\ Maria Manuela Sarmento \\ Instituto Superior de Contabilidade e Administração de Lisboa, Portugal \\ manuela.sarmento2@gmail.com \\ Maria Manuela Rebelo Duarte \\ Instituto Superior de Contabilidade e Administração de Lisboa, Portugal \\ manuelarebeloduarte@gmail.com
}

Resumo

\begin{abstract}
O objetivo principal deste estudo é identificar a diferença entre a perceção de estudantes finalistas dos cursos de Contabilidade do $1 .^{\circ}$ ciclo de ensino superior quanto às competências desenvolvidas no seu percurso de formação e a de contabilistas certificados sobre a importância dessas competências para o desenvolvimento da atividade profissional, no cenário português. Construíram-se dois questionários por inquérito, um para os estudantes finalistas e outro para os contabilistas certificados, tratando duas categorias de competências associadas ao ensino superior da Contabilidade: gerais e específicas. Obteve-se um total de 345 respostas para os estudantes finalistas e 392 para os contabilistas certificados. Na análise dos dados foi utilizado o método estatístico descritivo. A análise aos resultados permite concluir que os estudantes finalistas percecionam a capacidade de trabalhar em equipa como a competência geral mais desenvolvida, enquanto os contabilistas certificados consideram a capacidade de organização como a mais importante para a atividade profissional. A compreensão da linguagem técnica contabilística é a competência específica percecionada como a mais importante e a mais desenvolvida na formação superior. Procurou-se acrescentar evidência científica que contribui para um melhor conhecimento das competências que os estudantes, futuros contabilistas, percecionam que devem obter para atender às necessidades dos empregadores. Esta investigação pode, também, servir de fundamento para promover futuras mudanças nos métodos de ensino, procurando uma maior convergência entre a formação superior de Contabilidade e o que o mercado de trabalho procura.
\end{abstract}

Palavras-chave: Ensino superior; ensino em contabilidade; ompetências; perceção dos estudantes; perceção dos contabilistas certificados; Portugal.

Abstract
The main objective of this study is to identify the difference between the perception of final year
students in Accounting courses in the 1st cycle of higher education regarding the skills developed
Algarves: A Multidisciplinary e-Journal, 39-2021.
2182-5580 @ ESGHT - University of the Algarve, Portugal.

To cite this article: Domingos, A. M., Sarmento, M. M. \& Duarte, M. M. R. (2021). As competências deenvolvidas no ensino superior de contabilidade e sua imporância para a profissão: O cenário português. Dos Algarves: $A$ Multidisciplinary e-Journal, 39, 95-118. DOI: 10.18089/DAMeJ.2021.39.6 


\begin{abstract}
in their degree course and the importance of these skills to certified accountants for their professional development in the Portuguese context. Two questionnaire surveys were designed, one for final year students and the other for certified accountants, dealing with two categories of skills associated with higher education in accounting: general and specific. A total of 345 responses were obtained from final year students and 392 from certified accountants. In the data analysis, descriptive statistical methods were used. The analysis of the results allows us to conclude that the final year students perceive the ability to work as a team as the most developed general competence, while certified accountants consider organizational capacity as the most important for professional activity. Understanding the technical accounting language is the specific skill perceived as the most important and the most developed in higher education. We sought to add scientific evidence that contributes to a better knowledge of the skills that students and future accountants perceive they must obtain to meet employers' needs. This research can also serve as a foundation to promote future changes in teaching methods by seeking a greater convergence between higher education in Accounting and what the labor market demands.
\end{abstract}

Keywords: Higher education; accounting education; skills; students' perceptions; certified accountants' perceptions; Portugal.

\title{
1. Introdução
}

A dinâmica do ambiente global de negócios e os avanços tecnológicos manifestaram-se em rápidas mudanças para as organizações, as quais têm ajustado as suas práticas e procurado destacar-se perante a concorrência (Ceitil, 2016).

A destreza, a capacidade para resolver problemas, a iniciativa e a criatividade, articuladas com os conhecimentos de nível superior, são fatores que cada vez mais são privilegiados pelas entidades empregadoras (Kavanagh \& Drennan, 2008).

Jones (2010) defende que, cada vez mais, os profissionais de Contabilidade são procurados para realizar trabalho de consultoria, o que, na opinião do autor, significa que devem possuir conhecimento quer do contexto global e do ambiente económico em que a empresa se insere, quer do funcionamento interno das organizações e das posições das diversas partes interessadas, quer ainda sobre o uso das tecnologias da informação e da forma como as empresas atuam e aplicam os conceitos éticos inerentes à profissão. Para o autor, na sociedade globalizada atual, o profissional de Contabilidade é parte integrante de uma equipa, ambiente em que as capacidades de comunicação, a análise crítica e analítica, o trabalho em grupo, as capacidades interpessoais, a flexibilidade, a iniciativa, a criatividade e a inovação são bastante valorizadas.

De acordo com a International Federation of Accountants (IFAC, 2005), o Professional Accountant in Business (PAIB) conta com uma vasta área de ação e inumeráveis responsabilidades, nomeadamente no âmbito da Contabilidade de Gestão e da Gestão Financeira, considerando que esta profissão tem, assim, um enorme valor de alcance social.

Segundo alguns investigadores, o desempenho dos estudantes em cursos de Contabilidade ao longo dos anos tem sido consistentemente baixo (Bui \& Porter, 2010; Jackling \& De Lange, 2009; Kavanagh \& Drennan, 2008). Arquero e Fernández-Polvillo (2019) indicam que a divergência entre a realidade e as perceções dos estudantes pode ter origem na conceção errada de quais são as tarefas de um contabilista e as competências necessárias para um profissional no século XXI. Note-se que, embora a visão não seja estereotipada, os 
estudantes parecem não estar claros de que as tarefas contabilísticas requerem grupos de trabalho multidisciplinares cada vez mais integrados e comunicação com profissionais de outros perfis, o que exige que se complemente o simples relatório de números para poder explicar as implicações desses números.

Assim sendo, faz sentido discutir a adequabilidade da formação atual do profissional de Contabilidade à luz das novas exigências socioprofissionais, para melhor conhecer as necessidades emergentes em matéria de competências, procurando enfrentar os desafios desta área do conhecimento, nas suas vertentes teórica e prática, e contribuir com uma representação pessoal das exigências pedagógicas do ensino da Contabilidade no $1 .^{\circ}$ ciclo do ensino superior.

Desta forma, este estudo tem como objetivo identificar a diferença entre a perceção de estudantes finalistas dos cursos de Contabilidade do $10^{\circ}$ ciclo de ensino superior quanto às competências desenvolvidas no seu percurso de formação e a de contabilistas certificados sobre a importância dessas competências para o desenvolvimento da atividade profissional, no cenário português. Para além disso, analisar se este desenvolvimento/importância difere entre competências gerais e específicas.

A abordagem metodológica usada neste estudo foi a positivista, uma vez que assenta apenas em factos recolhidos nas fontes de informação utilizadas, como artigos científicos e normativo nacional e internacional. Para a concretização dos objetivos, o método usado foi o método dedutivo que resultou na elaboração de dois inquéritos para a recolha das perceções dos estudantes finalistas, inscritos em 2013/2014, nos cursos de Contabilidade do 1. ${ }^{\circ}$ ciclo e dos contabilistas certificados com inscrição ativa na Ordem, à data de 2014.

O artigo está dividido em quatro secções. A primeira secção explora a revisão da literatura sobre o desenvolvimento de competências gerais e específicas no ensino superior de Contabilidade. Na segunda secção, é apresentada a metodologia da investigação. A terceira secção efetua a análise e discussão dos dados obtidos das respostas aos inquéritos por questionário. A quarta e última secção apresenta as principais conclusões deste estudo.

\section{Desenvolvimento de competências no ensino superior}

A palavra competência tem origem no latim competentia, um nome derivado de competere e que significa a qualidade de quem é capaz de apreciar e resolver certo assunto, de fazer determinada coisa, com capacidade, aptidão e idoneidade.

Da revisão da literatura efetuada, verifica-se que não existe um conceito aceite universalmente, variando consoante o contexto ou o campo em que é utilizado. Ainda assim, é possível verificar a concordância no que respeita a ser uma combinação de conhecimentos, capacidades, aptidões e outras características individuais que podem ser medidas fiavelmente e mostrar a sua diferenciação no desempenho (Rouco \& Sarmento, 2012).

Até aos dias de hoje, tanto as Instituições de Ensino Superior (IES) como os profissionais têm-se confrontado com a questão das competências que os alunos, eternos aprendizes, devem adquirir, de modo a conseguirem competir eficazmente no mercado de trabalho (Jackling \& De Lange, 2009). 
De acordo com Van der Klink, Boon e Schlusmans (2007), a ideia de que a realidade se torna mais complexa e mais dinâmica fez aumentar, no ensino superior, a perceção de que a aquisição de conhecimentos (técnicos) é insuficiente para lidar com essa crescente complexidade, verificando-se um fenómeno de substituição do conhecimento pela ciência. Os autores referem que possuir a capacidade e a motivação para continuar a aprender é determinante para atrair as organizações.

Estas mudanças nas organizações têm, obviamente, consequências no ensino superior. Espera-se dos diplomados do ensino superior que, além de competências profissionais (específicas da profissão), possuam também competências de aprendizagem, competências sociais e competências de carreira (todas competências gerais), de forma a garantir empregabilidade também a longo prazo. Estas competências constituem uma parte fundamental da aptidão dos trabalhadores na sociedade pós-industrial e devem merecer a apropriada atenção nos programas curriculares do ensino superior (Van der Klink et al., 2007).

A abordagem por competências requereu uma mudança de paradigma e constituiu, sem dúvida, o maior e o mais complexo desafio que foi colocado às IES do espaço europeu e, em particular, às portuguesas. À missão de instruir, elemento-chave do modelo escolar outrora em vigor, junta-se também a missão de qualificar, tornando os estudantes capazes de empreender e de realizar, com êxito, um percurso profissional e pessoal ou social, através do domínio de competências profissionais e sociais. Tendencialmente, a missão de qualificar, entendida no sentido de disponibilizar aos estudantes um conjunto de recursos e "ensinar" a mobilizar esses recursos para a resolução de problemas reais, deverá ser a função principal das IES, deixando para segundo plano a missão de instruir (Van der Klink et al., 2007).

Verifica-se, então, que para lidar com os novos desafios da globalização e do avanço das tecnologias de informação, é importante olhar para o ensino da Contabilidade de uma forma estratégica para melhor alinhar a aprendizagem com as exigências do mercado de trabalho. O ensino da Contabilidade deve desenvolver nos estudantes o gosto pela aprendizagem, tendo sido necessário modificar o modelo de ensino centrado na transmissão de conhecimentos, que se mostrava desatualizado e obsoleto, e implementar novas estratégias (Almeida et al., 2015; Bolívar, 2007).

\subsection{Competências gerais versus competências especifícas}

Ceitil (2016) destaca a existência de dois tipos de competências: as específicas (mais ligadas a uma atividade profissional ou tarefa, encontrando-se hierarquizadas) e as transversais ou gerais. Segundo o autor, o conceito de competências gerais distingue-se do de competências específicas pela apresentação de duas características: a transversalidade (inexistência de especificidades e adaptação a contextos particulares) e a transferibilidade, adquiridas num contexto e passíveis de serem exercidas em contextos diferentes.

A literatura contém diferentes tentativas de classificar a multiplicidade de definições das competências (Cabral-Cardoso, Estêvão \& Silva, 2006). Apesar da diversidade, em geral, todas as classificações podem ser organizadas nas seguintes categorias: (i) as competências 
gerais ou transversais; e (ii) as competências técnicas específicas da função (Cabral-Cardoso et al., 2006).

Da revisão da literatura efetuada, constata-se que as competências gerais têm vindo a ganhar destaque, na medida em que se defende que as competências técnicas (as que se referem ao conhecimento adquirido pela experiência e formação profissionais, ou seja, as específicas da profissão) são presumidas e que são as competências gerais associadas ao sucesso na carreira profissional (Van der Klink et al., 2007; Kavanagh \& Drennan, 2008; Jackling \& De Lange, 2009; Paisey \& Paisey, 2010; Neves, Garrido \& Simões, 2015).

No estudo desenvolvido por Kavanagh e Drennan (2008), a 322 estudantes da licenciatura em Contabilidade e a 28 contabilistas em exercício de funções, na Austrália, foi possível concluir que os estudantes estão consciencializados no que respeita às expectativas das entidades empregadoras quanto à necessidade de possuir competências de comunicação, analíticas e de trabalho em grupo. Verificou-se, também, que quer da parte dos estudantes, quer das entidades empregadoras, há uma concordância quanto à opinião de que as competências não técnicas e as competências profissionais gerais, que consideram essenciais para o exercício da profissão de contabilista, não estão a ser satisfatoriamente desenvolvidas nos planos de curso. Os autores apuraram, ainda, que as entidades empregadoras, aquando da contratação de diplomados, privilegiam a análise e resolução de problemas, o conhecimento e perceção do negócio em termos de contexto real e as competências técnicas básicas.

O estudo de Jackling e De Lange (2009), no qual foram inquiridos 174 licenciados em Contabilidade, entre 2000 e 2003, e entrevistados 12 gestores de recursos humanos de nacionalidade australiana, mostra que as entidades empregadoras exigem uma vasta gama de competências gerais que os diplomados em Contabilidade indicaram não estarem a ser adequadamente ensinadas nos cursos que frequentaram. Os autores concluíram, ainda, que as áreas de divergência na perspetiva das entidades empregadoras são: a capacidade de trabalhar em equipa, a liderança, a comunicação verbal e as capacidades interpessoais dos diplomados.

Paisey e Paisey (2010) também argumentaram que, embora o conhecimento técnico seja a base para uma carreira em Contabilidade, a empregabilidade nesta área depende muito do nível de competências gerais que um diplomado possui.

Neves et al. (2015) defendem que, atualmente, para além dos conhecimentos técnicos, o colaborador de uma organização precisa de reunir um conjunto de competências gerais de carácter pessoal e interpessoal, que o capacite a encarar e a ultrapassar a diversidade de situações e oportunidades profissionais com que é confrontado diariamente. Os autores indicam as capacidades de adaptação, reflexão, flexibilidade, autonomia, iniciativa, liderança, comunicação, trabalho em equipa, controlo emocional, capacidade de organização, de decisão, de resolução de problemas, inovação, criatividade, gestão de conflitos e negociação.

Cory e Pruske (2012), com o objetivo de analisar o ponto de vista dos profissionais de Contabilidade dos Estados Unidos sobre as competências e nível de conhecimentos que os alunos deveriam possuir antes de entrarem no mercado de trabalho, efetuaram uma pesquisa com 464 profissionais. Os autores concluíram ser fundamental para a futura 
empregabilidade dos alunos que os planos dos cursos de Contabilidade contemplassem unidades curriculares (UC) que desenvolvam o domínio da tecnologia relacionada com a prática contabilística atual, como é o caso do pacote Office do Windows. Também consideraram ser fundamental os alunos terem criatividade em solucionar problemas, serem sensíveis às questões éticas e entenderem as terminologias de informática.

Aryanti e Adhariani (2020) analisaram, na Indonésia, a perceção de 103 estudantes finalistas, inscritos em cursos de Contabilidade, no ano letivo de 2013/2014, e a expectativa de 51 entidades empregadoras, relativamente às competências gerais e conhecimentos específicos na área, necessários aos graduados em Contabilidade. Os autores concluíram existir uma lacuna entre a perceção dos estudantes e a expectativa dos empregadores relativamente às competências gerais dos graduados, não acontecendo o mesmo em relação aos conhecimentos específicos na área.

Se, por um lado, alguns estudos apontam para a escassez de competências gerais desenvolvidas pelos diplomados em Contabilidade, outros estudos indicam formas pelas quais estes tipos de competências podem estar a ser mais bem desenvolvidos ao longo dos cursos. Uma dessas metodologias são os modelos de simulação inseridos em metodologias̃ de aprendizagem baseada em problemas (Problem Based Learning - PBL) presentes em estudos efetuados em Portugal (Almeida, Dias \& Pinheiro, 2009; Almeida et al., 2015; e Domingos, Sarmento \& Duarte, 2019) e no Brasil (Martins, Espejo \& Frezatti, 2016). Outra metodologia que, também, tem contribuído para o desenvolvimento das competências gerais são os estágios curriculares, conforme referem Paisey e Paisey (2010) para a realidade escocesa e Covas, Soares e Pimentel (2017), para a realidade portuguesa.

Almeida et al. (2009) inquiriram 284 estudantes finalistas de um instituto politécnico público português, no ano letivo de 2007/2008, com o objetivo de validar a utilização da simulação empresarial no processo de consolidação de competências e/ou a aquisição (reaquisição) das mesmas. Os autores puderam concluir que os estudantes dão muita importância à contribuição da unidade curricular (UC) no processo de aquisição de competências, encarando a aplicação das novas tecnologias de simulação, no ensino da Contabilidade, como uma mais-valia.

Almeida et al. (2015) analisaram a aquisição de competências na UC Projeto em Simulação Empresarial (PSE) num instituto politécnico público português, tendo inquirido 121 estudantes finalistas, no ano letivo 2014/2015, e verificaram que $92 \%$ concorda que a UC contribui para o desenvolvimento da capacidade de compreensão dos temas no âmbito do seu curso e $88 \%$ considera que esta UC permite a aplicação prática de conceitos. Os autores verificaram, ainda, que cerca de $77 \%$ dos alunos inquiridos considera que o PSE pode contribuir para um melhor desempenho profissional. Os autores apontaram como principais vantagens das práticas de simulação empresarial: levar a uma visão prática da profissão; desenvolver a capacidade de trabalhar sob pressão de tempo e volume de tarefas; desenvolver a capacidade de trabalhar em grupo; desenvolver a análise crítica em relação ao seu próprio trabalho e ao de terceiros; aperfeiçoar a capacidade de expressão oral e escrita e desenvolver no aluno os valores da liderança e do trabalho em equipa típicos de uma organização empresarial viva (que dificilmente se aprendem durante a fase de estudo individual). 
Martins et al. (2016) observaram a operacionalização do método PBL, durante seis meses, no ano de 2013, na UC Contabilidade de Gestão do curso de Contabilidade de uma IES pública brasileira, através da observação direta de 38 estudantes. Os autores comprovaram que a integração entre os académicos e as empresas a partir da utilização dos problemas práticos e reais trazidos pelos alunos do ambiente de trabalho proporcionou a vantagem de o estudante aumentar o potencial de resolução de problemas de ordem prática e profissional e, de a empresa beneficiar, uma vez que poderá receber, futuramente, profissionais qualificados, aptos a efetuar pesquisas e solucionar problemas. Os autores concluíram, assim, que o PBL ajuda a envolver os estudantes, tendo em conta que o desejo de participação e comunicação em ambiente interativo com utilização de ferramentas tecnológicas são as grandes marcas da atual geração.

Domingos et al. (2019) compararam as perceções de 345 estudantes finalistas de IES portuguesas, no ano letivo 2013/2014, com a opinião das principais 10 empresas empregadoras de recém-licenciados em Contabilidade, quanto às competências gerais e específicas desenvolvidas na licenciatura. Os resultados obtidos indicaram que estudantes e empregadores consideram que a "capacidade de trabalhar em equipa" e a "compreensão da linguagem técnica contabilística” são as competências mais desenvolvidas. Concluíram, ainda, que a maioria dos empregadores acredita que as IES portuguesas estão a preparar os alunos suficientemente bem para o local de trabalho, embora, ainda exista falta de conexão entre a teoria e a prática. Não obstante, têm vindo a observar que os cursos de Contabilidade evoluíram consideravelmente nos últimos anos devido à existência de práticas de simulação empresarial, que permite uma visão mais prática, proporcionando, assim, uma melhor preparação para o mercado de trabalho.

Paisey e Paisey (2010) avaliaram o desenvolvimento de competências, durante um ano de estágio, em alunos de duas universidades escocesas, do curso de Contabilidade e Finanças. Os autores puderem concluir que o estágio curricular proporciona o desenvolvimento de competências de forma complementar ao ambiente exclusivamente académico contribuindo, assim, para o desenvolvimento das competências técnicas e nãotécnicas necessárias para o profissional de Contabilidade exercer a sua atividade profissional.

Covas et al. (2017) avaliaram o contributo do estágio curricular e da simulação empresarial, no âmbito das licenciaturas em Contabilidade, a nível nacional, para a aquisição e/ou desenvolvimento de competências nos estudantes finalistas inscritos em 2015/2016. Os resultados demonstram que existem diferenças a nível da aquisição/desenvolvimento de competências nas duas UC, salientando que, atualmente, a implementação de qualquer prática educacional que vise promover as competências necessárias para o exercício da profissão e valorizadas pelo mercado de trabalho revela-se um incentivo relevante para o ensino superior.

Existe, por isso, a necessidade de estudar o ajustamento entre o sistema de ensino e o mercado de trabalho, de forma a criar um modelo de ensino superior que se pretende mais interativo e próximo da realidade, ensinando e simulando. Em Portugal, tanto os estágios curriculares ou, em alternativa, O PSE, já fazem parte dos ciclos de estudos, sendo inclusivamente um dos requisitos para que os estudantes licenciados em Contabilidade 
possam candidatar-se à admissão à Ordem dos Contabilistas Certificados (OCC). Deverá, assim, haver uma preocupação da parte das IES em espelhar da maneira mais aproximada quanto possível aquilo que é o mercado de trabalho português atual.

\subsection{Identificaçao das competências necessárias ao profissional de contabilidade}

A identificação das competências para preparar as variáveis a serem mensuradas passou por três fases: análise da revisão da literatura sobre o conceito de competência; análise das competências mais citadas na revisão da literatura e agregação das mesmas. No decurso do processo de agregação, foi necessário fundir o número de competências nos casos em que a essência de uma competência estava contida noutra já mencionada como, por exemplo, "Capacidade organizativa" e "capacidade de organização". Foi, também, indispensável dividir algumas, como é o caso da "capacidade de identificar problemas" e "capacidade de resolver problemas". Este procedimento permitiu tornar o conjunto de competências mais lógico e claro, evitando ideias repetidas e reduzindo, assim, os erros de interpretação por parte dos respondentes.

No processo de identificação das competências, para além daquelas que os autores presentes na revisão da literatura efetuada consideram como mais relevantes, foi, também, considerado o normativo que regula a profissão a nível nacional. As funções do contabilista certificado estão, atualmente, reguladas no artigo $10^{\circ}$ do Capítulo I (anterior artigo $6^{\circ}$ ) do Estatuto da OCC (anterior Estatuto da Ordem dos Técnicos Oficiais de Contas), aprovado pela Lei n. ${ }^{\circ}$ 139/2015, de 7 de setembro. Foi, ainda, tido em conta o normativo do International Accounting Education Standards Board (IAESB, 2015), organismo internacional que cria as normas na área da educação da Contabilidade.

De seguida, os Quadros 1 e 2 apresentam as competências a desenvolver no ensino superior de Contabilidade de acordo com a revisão da literatura efetuada. As competências são apresentadas na coluna 1 por tipologia e por ordem alfabética, e os estudos são apresentados por ordem cronológica, nas colunas 2 a 10.

Quadro 1. Competências gerais a desenvolver no $1 .^{\circ}$ ciclo do ensino superior de Contabilidade

\begin{tabular}{|c|c|c|c|c|c|c|c|c|c|}
\hline $\begin{array}{l}\text { COMPETÊNCIAS } \\
\text { GERAIS }\end{array}$ & $\begin{array}{l}\text { Almeida } \\
(2004)\end{array}$ & $\begin{array}{l}\text { Hassall } \\
\text { et al. } \\
(2005)\end{array}$ & $\begin{array}{c}\text { Cabral- } \\
\text { Cardoso } \\
\text { et al. } \\
(2006)\end{array}$ & $\begin{array}{l}\text { Kavanagh } \\
\text { e Drennan } \\
(2008)\end{array}$ & $\begin{array}{c}\text { Jackling } \\
\text { e De } \\
\text { Lange } \\
\text { (2009) }\end{array}$ & $\begin{array}{l}\text { Cory e } \\
\text { Pruske } \\
\text { (2012) }\end{array}$ & $\begin{array}{l}\text { Pan e } \\
\text { Perera } \\
\text { (2012) }\end{array}$ & $\begin{array}{l}\text { EOCC } \\
(2015)\end{array}$ & $\begin{array}{l}\text { IFAC } \\
(2017)\end{array}$ \\
\hline \multicolumn{10}{|c|}{ Competências Intelectuais } \\
\hline $\begin{array}{l}\text { Capacidade de } \\
\text { autocrítica }\end{array}$ & $x$ & & $x$ & & & & & & $x$ \\
\hline $\begin{array}{l}\text { Capacidade de } \\
\text { avaliar a } \\
\text { necessidade de } \\
\text { recorrer a } \\
\text { especialistas de } \\
\text { diferentes áreas }\end{array}$ & & & & & & & & $x$ & $x$ \\
\hline $\begin{array}{l}\text { Capacidade de } \\
\text { crítica }\end{array}$ & $x$ & & $x$ & & & & & & $x$ \\
\hline
\end{tabular}




\begin{tabular}{|c|c|c|c|c|c|c|c|c|c|}
\hline $\begin{array}{l}\text { COMPETÊNCIAS } \\
\text { GERAIS }\end{array}$ & $\begin{array}{l}\text { Almeida } \\
\text { (2004) }\end{array}$ & $\begin{array}{l}\text { Hassall } \\
\text { et al. } \\
(2005)\end{array}$ & $\begin{array}{l}\text { Cabral- } \\
\text { Cardoso } \\
\text { et al. } \\
(2006)\end{array}$ & $\begin{array}{c}\text { Kavanagh } \\
\text { e Drennan } \\
\text { (2008) }\end{array}$ & $\begin{array}{l}\text { Jackling } \\
\text { e De } \\
\text { Lange } \\
\text { (2009) }\end{array}$ & $\begin{array}{l}\text { Cory e } \\
\text { Pruske } \\
(2012)\end{array}$ & $\begin{array}{l}\text { Pan e } \\
\text { Perera } \\
(2012)\end{array}$ & $\begin{array}{l}\text { EOCC } \\
(2015)\end{array}$ & $\begin{array}{l}\text { IFAC } \\
(2017)\end{array}$ \\
\hline $\begin{array}{l}\text { Capacidade de } \\
\text { identificar } \\
\text { problemas }\end{array}$ & $x$ & $x$ & $x$ & $x$ & & $x$ & $x$ & & $x$ \\
\hline $\begin{array}{c}\text { Capacidade de } \\
\text { integração da } \\
\text { informação }\end{array}$ & & & & & & & & & $x$ \\
\hline $\begin{array}{l}\text { Capacidade de } \\
\text { pesquisa da } \\
\text { informação }\end{array}$ & & & & $x$ & & & & & $x$ \\
\hline $\begin{array}{l}\text { Capacidade de } \\
\text { resolver } \\
\text { problemas }\end{array}$ & $x$ & $x$ & $x$ & $x$ & $x$ & $x$ & $x$ & & $x$ \\
\hline $\begin{array}{l}\text { Capacidade de } \\
\text { raciocínio }\end{array}$ & & & & & & & & & $x$ \\
\hline $\begin{array}{c}\text { Capacidade para } \\
\text { analisar a } \\
\text { informação }\end{array}$ & $x$ & & & & & & & & $x$ \\
\hline $\begin{array}{l}\text { Capacidade para } \\
\text { tomar decisões }\end{array}$ & & $x$ & $x$ & $x$ & & & & & $x$ \\
\hline Criatividade & & & $x$ & $x$ & $x$ & $x$ & & & \\
\hline Cultura geral & $x$ & & $x$ & & & & & & \\
\hline $\begin{array}{l}\text { Julgamento } \\
\text { profissional }\end{array}$ & & & & & & & & & $x$ \\
\hline $\begin{array}{c}\text { Pensamento } \\
\text { inovador }\end{array}$ & & $x$ & & & & & & & $x$ \\
\hline \multicolumn{10}{|c|}{ Competências Pessoais } \\
\hline $\begin{array}{c}\text { Capacidade de } \\
\text { aprendizagem ao } \\
\text { longo da vida }\end{array}$ & & & $x$ & $x$ & & & & $x$ & $x$ \\
\hline $\begin{array}{c}\text { Capacidade de } \\
\text { trabalhar } \\
\text { autonomamente }\end{array}$ & $x$ & & $x$ & $x$ & & & & & \\
\hline $\begin{array}{c}\text { Capacidade para } \\
\text { trabalhar sob } \\
\text { pressão }\end{array}$ & $x$ & & $x$ & & & & & & \\
\hline $\begin{array}{c}\text { Ceticismo } \\
\text { profissional }\end{array}$ & & & & & & & & & $x$ \\
\hline $\begin{array}{c}\text { Gestão de } \\
\text { recursos }\end{array}$ & & & & $x$ & $x$ & & & & $x$ \\
\hline Gestão do tempo & & & & $x$ & & & $x$ & & $x$ \\
\hline $\begin{array}{c}\text { Mente aberta a } \\
\text { novas } \\
\text { oportunidades }\end{array}$ & & & $x$ & & & & & & $x$ \\
\hline \multicolumn{10}{|c|}{ Competências Interpessoais e de Comunicação } \\
\hline $\begin{array}{c}\text { Capacidade de } \\
\text { comunicação (oral } \\
\text { e escrita) }\end{array}$ & $x$ & $x$ & $x$ & $x$ & $x$ & & $x$ & & $x$ \\
\hline $\begin{array}{l}\text { Capacidade de } \\
\text { negociação }\end{array}$ & & & $x$ & $x$ & $x$ & & & & $x$ \\
\hline
\end{tabular}




\begin{tabular}{|c|c|c|c|c|c|c|c|c|c|}
\hline $\begin{array}{l}\text { COMPETÊNCIAS } \\
\text { GERAIS }\end{array}$ & $\begin{array}{l}\text { Almeida } \\
(2004)\end{array}$ & $\begin{array}{l}\text { Hassall } \\
\text { et al. } \\
(2005)\end{array}$ & $\begin{array}{l}\text { Cabral- } \\
\text { Cardoso } \\
\text { et al. } \\
(2006) \\
\end{array}$ & $\begin{array}{l}\text { Kavanagh } \\
\text { e Drennan } \\
(2008)\end{array}$ & $\begin{array}{l}\text { Jackling } \\
\text { e De } \\
\text { Lange } \\
\text { (2009) }\end{array}$ & $\begin{array}{l}\text { Cory e } \\
\text { Pruske } \\
\text { (2012) }\end{array}$ & $\begin{array}{l}\text { Pan e } \\
\text { Perera } \\
(2012)\end{array}$ & $\begin{array}{l}\text { EOCC } \\
(2015)\end{array}$ & $\begin{array}{l}\text { IFAC } \\
(2017)\end{array}$ \\
\hline $\begin{array}{c}\text { Capacidade de } \\
\text { relacionamento } \\
\text { interpessoal }\end{array}$ & & & $\mathrm{x}$ & $x$ & $x$ & & & & \\
\hline $\begin{array}{l}\text { Capacidade para } \\
\text { gerir conflitos }\end{array}$ & $x$ & & & & & & & & $x$ \\
\hline $\begin{array}{c}\text { Capacidade para } \\
\text { trabalhar em } \\
\text { equipa }\end{array}$ & $x$ & $x$ & $x$ & $x$ & $x$ & & $x$ & & $x$ \\
\hline $\begin{array}{c}\text { Comunicação } \\
\text { intercultural }\end{array}$ & & & & & & $x$ & & & $x$ \\
\hline Cooperação & & & & & & & & & $x$ \\
\hline \multicolumn{10}{|c|}{ Competências Organizacionais } \\
\hline $\begin{array}{c}\text { Capacidade de } \\
\text { avaliar a } \\
\text { qualidade do } \\
\text { trabalho realizado }\end{array}$ & & & & & & & & $x$ & \\
\hline $\begin{array}{l}\text { Capacidade de } \\
\text { liderança }\end{array}$ & & & $x$ & $x$ & & & $x$ & & $x$ \\
\hline $\begin{array}{c}\text { Capacidade de } \\
\text { motivar os outros }\end{array}$ & & & & & & & & & $x$ \\
\hline $\begin{array}{c}\text { Capacidade de } \\
\text { organização }\end{array}$ & & $x$ & & & & & & & \\
\hline $\begin{array}{l}\text { Capacidade para } \\
\text { delegar tarefas }\end{array}$ & & $x$ & & & & & & & $x$ \\
\hline $\begin{array}{c}\text { Capacidade para } \\
\text { utilizar as } \\
\text { tecnologias de } \\
\text { informação e } \\
\text { comunicação } \\
\end{array}$ & $x$ & $\mathrm{x}$ & $\mathrm{x}$ & $x$ & $x$ & $x$ & $x$ & & $x$ \\
\hline Gestão de pessoas & & & & & & & & & $x$ \\
\hline
\end{tabular}

Analisando as competências gerais que os autores ao longo do tempo consideram fundamentais desenvolver nos futuros profissionais da área da Contabilidade (Quadro 1), parece ser necessário que o currículo destes cursos contenha unidades curriculares capazes de dotar os estudantes de competências que permitam a identificação e resolução de problemas, a comunicação oral e escrita, o desenvolvimento do trabalho em equipa e a capacidade para utilizar as tecnologias de informação e comunicação. 
Quadro 2. Competências específicas a desenvolver no $10^{\circ}$ ciclo do ensino superior de Contabilidade

\begin{tabular}{|c|c|c|c|c|c|c|c|c|}
\hline $\begin{array}{l}\text { COMPETÊNCIAS } \\
\text { ESPECÍFICAS }\end{array}$ & $\begin{array}{l}\text { Almeida } \\
(2004)\end{array}$ & $\begin{array}{l}\text { Hassall } \\
\text { et al. } \\
(2005)\end{array}$ & $\begin{array}{l}\text { Kavanagh } \\
\text { e Drennan } \\
\text { (2008) }\end{array}$ & $\begin{array}{l}\text { Jackling } \\
\text { e De } \\
\text { Lange } \\
\text { (2009) }\end{array}$ & $\begin{array}{l}\text { Corye } \\
\text { Pruske } \\
(2012)\end{array}$ & $\begin{array}{l}\text { Pan e } \\
\text { Perera } \\
(2012)\end{array}$ & $\begin{array}{l}\text { EOCC } \\
(2015)\end{array}$ & $\begin{array}{l}\text { IFAC } \\
(2017)\end{array}$ \\
\hline \multicolumn{9}{|c|}{ Competências técnicas da profissão } \\
\hline $\begin{array}{l}\text { Capacidade de elaborar } \\
\text { orçamentos globais }\end{array}$ & $x$ & & & & $\mathrm{x}$ & & & \\
\hline $\begin{array}{l}\text { Capacidade de estruturar } \\
\text { um painel de gestão com } \\
\text { informação útil para a } \\
\text { tomada de decisão }\end{array}$ & $x$ & & & & & & & \\
\hline $\begin{array}{l}\text { Capacidade para aplicar o } \\
\text { conhecimento à prática }\end{array}$ & $x$ & & & $x$ & & & & \\
\hline $\begin{array}{c}\text { Capacidade para efetuar } \\
\text { uma análise financeira }\end{array}$ & $x$ & & & $x$ & & & & \\
\hline $\begin{array}{l}\text { Capacidade para preparar as } \\
\text { demonstrações financeiras }\end{array}$ & $x$ & & & $x$ & & & & \\
\hline $\begin{array}{c}\text { Capacidade para preparar } \\
\text { relatórios de desvios de } \\
\text { desempenho }\end{array}$ & $x$ & & & & & & & \\
\hline $\begin{array}{l}\text { Compreender a linguagem } \\
\text { técnica contabilística }\end{array}$ & $x$ & & $x$ & $x$ & & & & \\
\hline $\begin{array}{c}\text { Compreender os contextos } \\
\text { em que a Contabilidade } \\
\text { opera }\end{array}$ & $x$ & & & $x$ & & & & \\
\hline \multicolumn{9}{|c|}{ Routine accounting } \\
\hline $\begin{array}{c}\text { Capacidade de cumprir com } \\
\text { prazos e regras }\end{array}$ & $x$ & & & & & & & $x$ \\
\hline $\begin{array}{c}\text { Capacidade de planificar o } \\
\text { trabalho }\end{array}$ & & & & & & & $x$ & \\
\hline $\begin{array}{c}\text { Capacidade para organizar a } \\
\text { informação }\end{array}$ & $x$ & & & & & & & \\
\hline $\begin{array}{c}\text { Capacidade para reportar a } \\
\text { informação }\end{array}$ & $x$ & & & & & & $\mathrm{x}$ & $\mathrm{x}$ \\
\hline $\begin{array}{c}\text { Capacidade para tratar } \\
\text { dados }\end{array}$ & $x$ & & & & & & & \\
\hline \multicolumn{9}{|c|}{ Ética e profissionalismo } \\
\hline $\begin{array}{l}\text { Aplicar os requisitos éticos } \\
\text { (princípios, valores, } \\
\text { atitudes) da profissão }\end{array}$ & $x$ & & $x$ & $x$ & $x$ & $x$ & $x$ & $x$ \\
\hline
\end{tabular}

Observando as competências específicas que os autores ao longo do tempo consideram fundamentais para o exercício da atividade profissional (Quadro 2), verifica-se a importância da aplicação dos requisitos éticos da profissão e da compreensão da linguagem técnica contabilística.

\section{Metodologia da investigação}

Na sequência dos objetivos propostos, foi constituída uma metodologia composta por três fases distintas: a fase exploratória, a fase analítica e a fase conclusiva. A fase exploratória consistiu na recolha da informação, permitindo elaborar o enquadramento teórico do 
estudo, relacionando o ensino com o conceito de competência e estabelecendo a sua ligação à área científica da Contabilidade.

O passo seguinte, a fase analítica, passou pela recolha de dados. As alternativas de investigação empírica assentaram no tratamento de dados recolhidos e nas respostas ao inquérito por questionário aos estudantes finalistas dos cursos de $1 .^{\circ}$ ciclo de Contabilidade e aos contabilistas certificados. A recolha de dados foi efetuada através de um inquérito, à semelhança de outros estudos relacionados com esta temática, os quais também utilizam este instrumento na obtenção de dados.

A opção pela utilização do inquérito online baseou-se no facto de existir uma grande dispersão geográfica dos estudantes e dos contabilistas certificados, em Portugal, permitindo, assim, alcançar o máximo de respostas possível num curto espaço de tempo, com confidencialidade e anonimato dos respondentes (Evans \& Mathur, 2005).

Para validação das competências, submeteu-se o conjunto das 49 competências, apresentadas no Quadro 1, a uma comissão de validação constituída por 14 especialistas no domínio técnico e/ou científico na área da Contabilidade, de forma a verificar se estas competências seriam imprescindíveis para o desempenho da profissão de contabilista certificado.

A informação obtida foi analisada de forma global, não havendo lugar a interpretações individualizadas. Resultaram, assim, 27 competências, que constaram da segunda parte do questionário (Q6 a Q32) tendo-se desprezado respostas com uma percentagem de resposta positiva inferior a 75\% (Quadro 3).

Quadro 3. Validação das competências a desenvolver no ensino superior da Contabilidade

\begin{tabular}{|c|c|c|}
\hline \multirow{16}{*}{$\begin{array}{l}\text { COMPETÊNCIAS } \\
\text { GERAIS }\end{array}$} & Q6 & Capacidade de resolver problemas \\
\hline & Q7 & Capacidade de integração da informação \\
\hline & Q8 & Capacidade para analisar a informação \\
\hline & Q9 & Capacidade para utilizar as tecnologias de informação e comunicação \\
\hline & Q10 & Capacidade para trabalhar sob pressão \\
\hline & Q11 & Capacidade para trabalhar em equipa \\
\hline & Q12 & Capacidade de aprendizagem ao longo da vida \\
\hline & Q13 & Capacidade de crítica \\
\hline & Q14 & Capacidade de autocrítica \\
\hline & Q15 & Gestão do tempo \\
\hline & Q16 & Capacidade de relacionamento interpessoal \\
\hline & Q17 & Capacidade para tomar decisões \\
\hline & Q18 & Capacidade de raciocínio \\
\hline & Q19 & Capacidade de organização \\
\hline & Q20 & Capacidade de avaliar a qualidade do trabalho realizado \\
\hline & Q21 & Capacidade de comunicação (oral e escrita) \\
\hline \multirow{2}{*}{$\begin{array}{l}\text { COMPETÊNCIAS } \\
\text { ESPECÍFICAS }\end{array}$} & Q22 & Capacidade para aplicar o conhecimento à prática \\
\hline & Q23 & Capacidade para organizar a informação \\
\hline
\end{tabular}




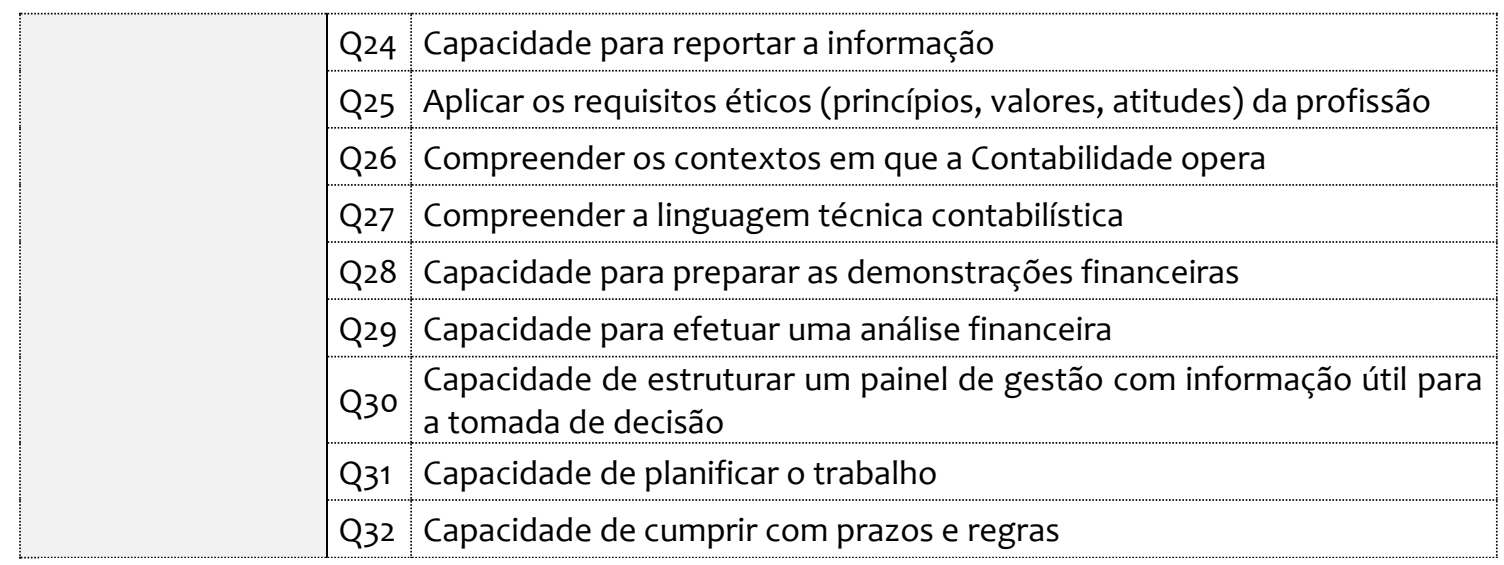

A fase conclusiva consistiu na interpretação dos resultados obtidos e respetivas conclusões, bem como na evidência dos contributos e limitações da investigação e sugestões para trabalhos futuros.

\subsection{Elaboração dos inquéritos por questionário}

Foram elaborados dois inquéritos por questionário: um para os estudantes finalistas e outro para os contabilistas certificados. Os inquéritos foram devidamente validados, pré testados e revistos por uma comissão de validação de 4 especialistas na área da Contabilidade. Os objetivos desta validação foram testar a compreensão e coerência das questões e a correção de eventuais erros na sua interpretação. Como resultado desta contribuição, surgiram os seguintes melhoramentos com o objetivo de reduzir os erros de interpretação por parte dos respondentes: divisão das competências por tipologia (gerais e específicas) e a colocação de uma breve descrição em cada uma, de maneira a evitar a dupla interpretação.

O questionário foi segmentado em duas partes: a primeira, com a caracterização demográfica dos respondentes; e a segunda parte com as 27 competências, divididas em 16 competências gerais e 11 competências específicas com as respetivas descrições. A divisão das competências em gerais e específicas e as suas descrições são o resultado da revisão da literatura efetuada aos vários artigos científicos e manuais de referência.

Foi utilizada a escala de Likert por ser uma das formas mais confiáveis de medir opiniões e perceções, tendo-se adotado uma escala ímpar de maneira a permitir a existência de um ponto médio, na medida em que para manter a neutralidade da escala é necessário ter uma simetria em relação à opção neutra de seleção. Neste estudo, sendo que cada nível faz corresponder um grau de concordância/importância, de forma a perceber a intensidade da opinião dos respondentes, utilizou-se uma escala com 7 níveis para permitir melhor discriminação, maior consistência interna e maior confiabilidade da escala. As opções para os estudantes finalistas vão de (1) Discordo Totalmente a (7) Concordo Totalmente. Para os contabilistas certificados, utilizaram-se as opções de (1) Sem importância a (7) Muito importante. 


\subsection{Amostra}

Foram objeto de análise neste estudo os 41 cursos de licenciaturas existentes em 28 IES portuguesas, com o $10^{\circ}$ ciclo de estudos em Contabilidade e, acreditados pela Agência de Avaliação e Acreditação do Ensino Superior (A3ES), com alunos inscritos no ano letivo 2013/2014.

As licenciaturas abrangidas no estudo contemplaram os cursos inseridos no grupo com o código 344, designado de Contabilidade e Fiscalidade, da Classificação Nacional das Áreas de Educação e Formação (CNAEF), aprovada pela Portaria n. ${ }^{\circ}$ 256/2005, de 16 de março.

A dimensão da amostra dos estudantes finalistas foi calculada atendendo ao total de inscritos no último ano dos cursos de Contabilidade em análise, ou seja, $\mathrm{N}=2608$ indivíduos. Para um nível de confiança de $95 \%$ e um nível de precisão $\mathrm{D}=+5 \%$, a amostra deve ter a dimensão de $n=335$ estudantes finalistas.

$O$ inquérito aos estudantes finalistas e aos contabilistas certificados foi construído através da plataforma "GoogleDocs". No caso dos estudantes, foi enviado um email aos responsáveis das licenciaturas em estudo, a solicitar que fosse disponibilizado o link do inquérito aos seus alunos. Obteve-se um total de 357 respostas, das quais 345 foram consideradas válidas.

Quanto aos contabilistas certificados em Portugal, foram considerados apenas aqueles que tinham a inscrição ativa na Ordem dos Contabilistas Certificados (OCC), à data de 2014, tendo-se pedido a colaboração da OCC, via email, para obter o total desta população. Assim, para um nível de confiança de $95 \%$ e um erro amostral de $\pm 5 \%$, o cálculo da amostra para populações finitas ( $\mathrm{N}=71825)$ apresentou uma dimensão de 382 contabilistas certificados. $\mathrm{O}$ link do inquérito esteve disponível na página institucional da OCC entre julho de 2014 e maio de 2015, e foi entregue numa sessão de formação, realizada em Lisboa. Foram obtidas 434 respostas, das quais 392 foram consideradas válidas.

\subsection{Análise de dados}

Em termos de análise da informação dos inquéritos por questionário, e com o intuito de determinar a forma de distribuição dos dados na escala dos valores possíveis, recorreu-se a técnicas de estatística descritiva e de análise exploratória dos dados. Na caracterização da amostra em estudo foi utilizada a frequência relativa para as variáveis qualitativas.

De forma a cumprir com os objetivos de investigação, a análise das competências mais desenvolvidas para os estudantes finalistas e mais importantes para os contabilistas certificados, será feita com recurso a uma tabela de comparação de médias para a análise individual de cada competência.

No que respeita às medidas de tendência central, foram utilizadas a média aritmética ponderada, a mediana e a moda, que permitiram efetuar uma comparação da tendência das respostas dos estudantes e dos contabilistas certificados.

Relativamente às medidas de dispersão, apenas se recorreu ao desvio-padrão, para a análise da variabilidade dos dados. 


\section{Análise e discussão dos resultados}

Neste ponto é efetuada a caracterização dos inquiridos e uma análise da informação obtida a partir do questionário aos estudantes finalistas e aos contabilistas certificados.

\subsection{Perfil dos respondentes}

Na Tabela 1 (estudantes finalistas) e na Tabela 2 (contabilistas certificados) são apresentadas as cinco primeiras perguntas que permitiram conhecer o perfil dos respondentes.

Tabela 1. Perfil dos estudantes finalistas $(\mathrm{N}=345)$

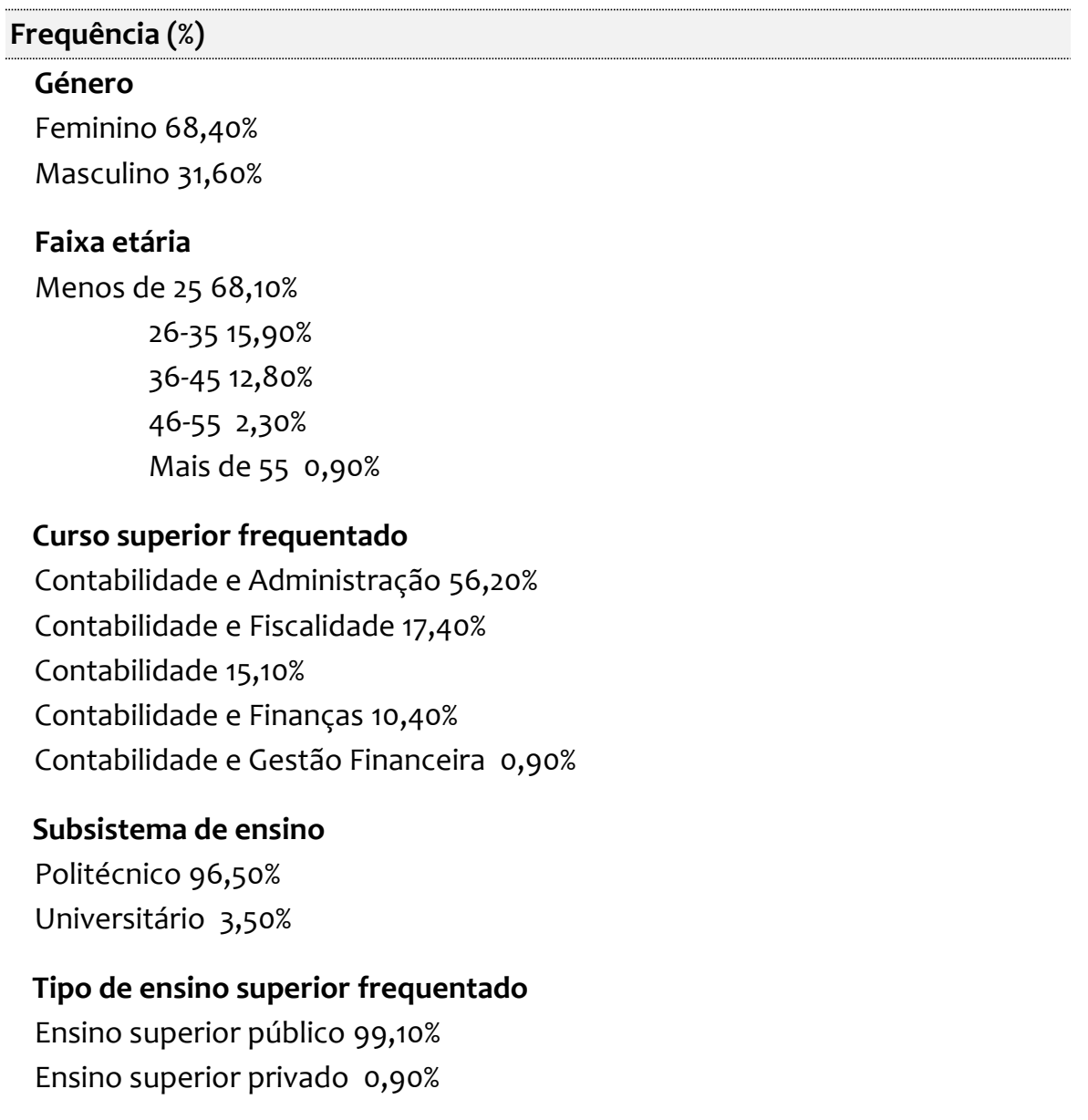

Analisando a Tabela 1, verifica-se que a maioria dos estudantes finalistas pertencem ao género feminino $(68,4 \%)$ e têm menos de 25 anos (68,1\%). A maioria dos respondentes frequentaram o curso de Contabilidade e Administração $(56,2 \%)$ e pertencem a institutos politécnicos (96,5\%), do ensino superior público (99,10\%).

Para os contabilistas certificados, foram analisadas as seguintes características: género, faixa etária, curso de formação base, anos de experiência profissional e exercício da profissão, conforme Tabela 2. 
Tabela 2. Perfil dos contabilistas certificados $(\mathrm{N}=392)$

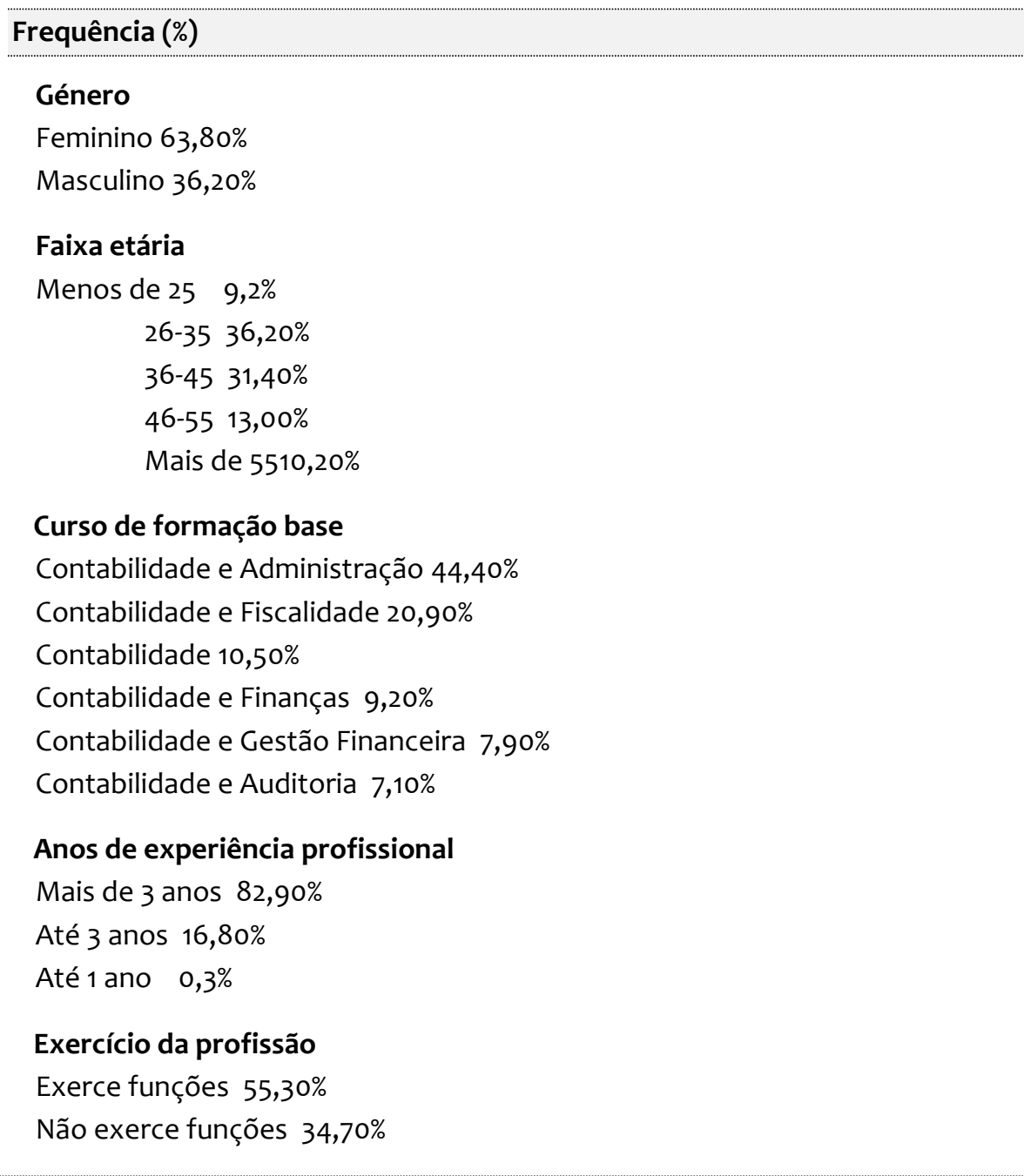

Os resultados da Tabela 2 demonstram que a maioria dos contabilistas certificados respondentes pertencem ao género feminino (63,8\%) e têm entre 26 e 35 anos (36,2\%). Observa-se que $44,4 \%$ detêm o curso de Contabilidade e Administração, têm mais de 3 anos de experiência profissional (82,9\%) e 55,3\% estão, atualmente, a exercer a profissão.

Após conhecer o perfil dos respondentes, partiu-se para a análise descritiva das variáveis de pesquisa, com o intuito de verificar a percentagem de resposta dos dois grupos de inquiridos em cada questão.

\subsection{Estatística descritiva para as competências gerais}

Neste ponto, apresenta-se uma síntese das principais estatísticas relativamente às 16 competências gerais, para os estudantes finalistas e para os contabilistas certificados (Tabela 3). 
Tabela 3. Perceção de estudantes finalistas e contabilistas certificados em relação às competências gerais

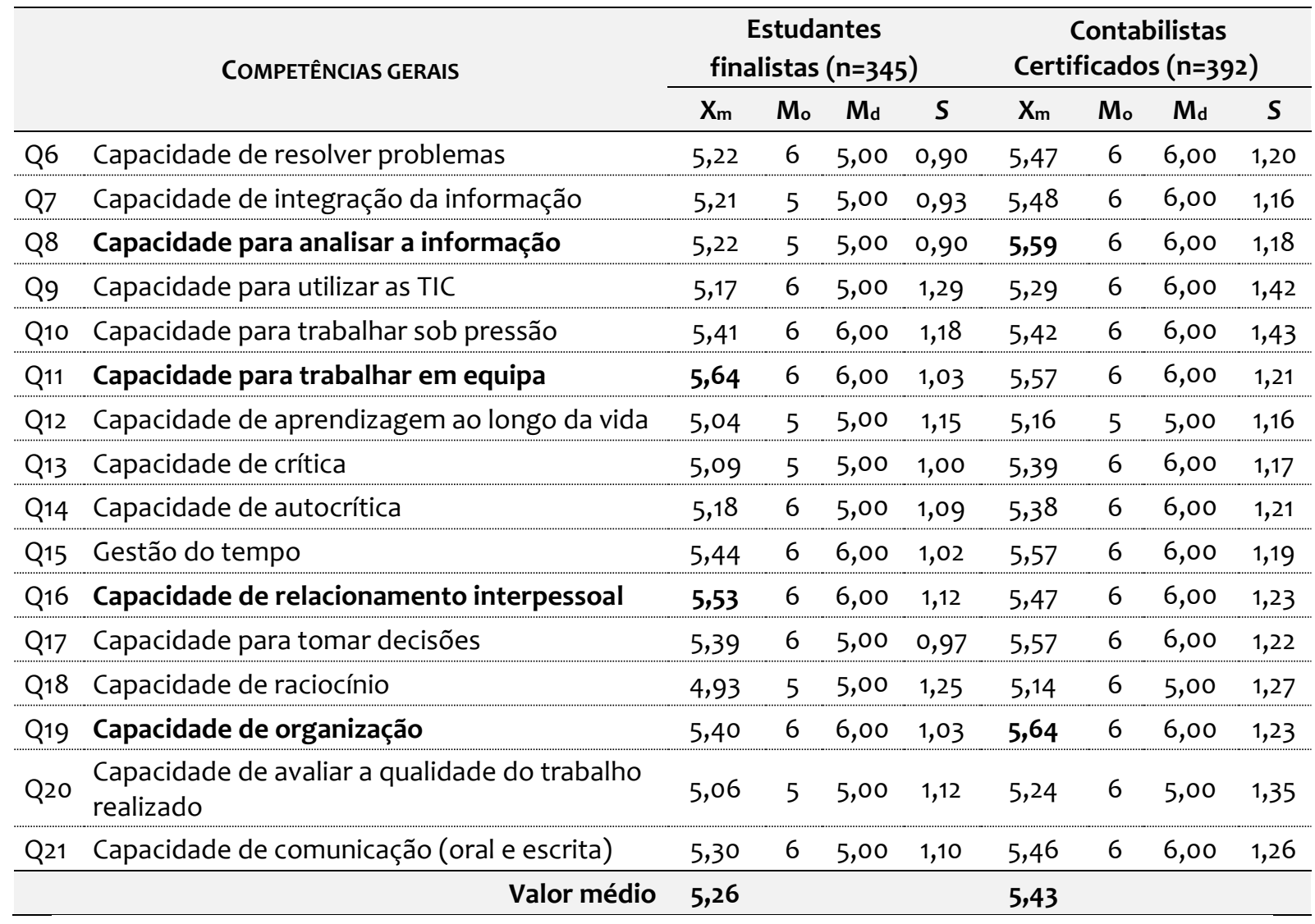

Legenda: $X_{m}$ - Média da amostra; $M_{o}-$ Moda; $M_{d}-$ Mediana; S - Desvio-padrão.

Observando a Tabela 3, é possível verificar que os estudantes finalistas demonstram baixa concordância com o desenvolvimento das competências gerais no seu percurso de formação superior, uma vez que a média das respostas apresenta o valor de $x_{m}=5,26$ correspondente ao grau de "Concordo pouco" na escala de concordância utilizada. Esta análise é reforçada pela mediana, onde se verifica que, em 11 das 16 competências apresentadas, metade dos estudantes "Concorda pouco" com o seu desenvolvimento $\left(M_{d}=5,00\right)$. Não obstante, o resultado mais comum para 10 das 16 competências gerais apresentadas foi de $M_{0}=6$, correspondente ao grau de "Concordo em grande parte".

É, ainda, possível verificar que a "capacidade para trabalhar em equipa" $\left(\mathrm{x}_{\mathrm{m} 11}=5,64\right)$ e a "capacidade de relacionamento interpessoal" $\left(x_{m 16}=5,53\right)$ são as competências gerais percecionadas pelos estudantes como mais desenvolvidas ao longo do seu percurso académico. Pelo contrário, a "capacidade de aprendizagem ao longo da vida" $\left(x_{m 12}=5,04\right)$ e a

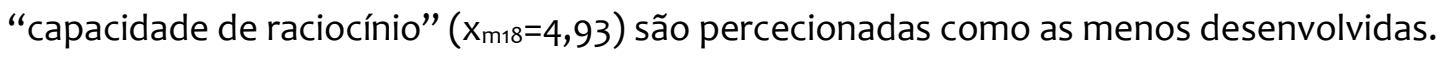

Através da Tabela 3, verifica-se, também, que a capacidade para utilizar as Tecnologias de Informação e Comunicação (TIC) é a que, nas respostas dos estudantes finalistas, apresenta o desvio-padrão mais elevado, concluindo-se, assim, que existem muitas respostas extremadas, motivadas, provavelmente, pelo facto de se analisarem todas as IES nacionais. 
Quanto aos contabilistas certificados, no geral, são da opinião que as competências gerais são importantes para o exercício da sua atividade profissional, mas com graus de importância diferentes. A média das respostas evidencia o valor de $x_{m}=5,43$ correspondente ao grau de "Importância média" na escala de importância utilizada.

Para os contabilistas certificados, destaca-se a capacidade para trabalhar sob pressão com o desvio-padrão mais elevado, indicando uma certa divisão de opiniões: uns que consideram imprescindível o saber lidar com a pressão no exercício da atividade profissional e outros que não o consideram.

Quanto à perceção dos contabilistas certificados, verifica-se, através da Tabela 3, que a "capacidade de organização" $\left(x_{m 19}=5,64\right)$ e a "capacidade para analisar a informação" $\left(x_{m 8}=5,59\right)$ são as competências gerais consideradas mais importantes para o desempenho da profissão. Em oposição, a "capacidade de aprendizagem ao longo da vida" $\left(x_{m 12}=5,16\right)$ e a "capacidade de raciocínio" $\left(x_{m 18}=5,14\right)$ apresentam os valores médios mais baixos, o que revela que, tendencialmente, os contabilistas certificados consideram que estas competências não são tão importantes para o desempenho da profissão.

Os resultados da presente investigação indicam que os estudantes finalistas consideram a capacidade para trabalhar em equipa como a competência geral mais desenvolvida ao longo do percurso de formação superior. Em alguns estudos desenvolvidos acerca das competências que são importantes e intrínsecas ao profissional de Contabilidade, verificouse que o mercado de trabalho considera que a competência para trabalhar em equipa é impreterível para os diplomados serem bem-sucedidos, logo as mesmas terão de ser imprescindivelmente desenvolvidas no contexto do ensino superior de Contabilidade (Kavanagh \& Drennan, 2008; Paisey \& Paisey, 2010; Pan \& Perera, 2012; Neves et al., 2015).

Contudo, o estudo desenvolvido por Jackling e De Lange (2009) indicava que os diplomados em Contabilidade não estavam a desenvolver adequadamente as competências gerais, sendo a capacidade de trabalhar em equipa uma das competências alvo de divergência. Os resultados obtidos neste estudo indicam exatamente o contrário, talvez, pela implementação de novas metodologias de ensino, como as práticas de simulação empresarial ou os estágios curriculares, que têm permitido estimular no estudante um conjunto de competências que vão ao encontro dos objetivos do ensino superior baseado em competências, tornando a aprendizagem ativa e participada, conforme referem Almeida et al. (2015) e Covas et al. (2017).

Outro dos resultados obtidos é o facto de a capacidade de organização ser referida pelos contabilistas certificados como a competência geral mais importante para o desempenho da profissão. Estes resultados vão ao encontro do que o IAESB preconiza na Norma Internacional de Educação (NIE) 3 quanto às competências que um profissional de Contabilidade deve possuir. A capacidade de organizar e delegar tarefas está inserida nas competências organizacionais, as quais têm vindo a adquirir, de acordo com a revisão da literatura efetuada, uma importância crucial para os profissionais de Contabilidade. Esta situação deriva do facto de hoje o profissional da Contabilidade ser chamado a mostrar-se mais ativo e a ter mais influência na gestão das organizações e no seu dia a dia. 


\subsection{Estatística descritiva quanto às competências específicas}

Nesta subsecção, apresenta-se uma síntese das principais estatísticas relativas às variáveis em estudo na segunda parte do inquérito, quanto às 11 competências específicas, para os dois grupos de inquiridos, conforme a Tabela 4.

Tabela 4. Perceção de estudantes finalistas e de contabilistas certificados em relação às competências específicas

\begin{tabular}{|c|c|c|c|c|c|c|c|c|c|}
\hline & \multirow[t]{2}{*}{ COMPETÊNCIAS ESPECÍFICAS } & \multicolumn{4}{|c|}{$\begin{array}{l}\text { Estudantes finalistas } \\
\qquad(\mathrm{n}=345)\end{array}$} & \multicolumn{4}{|c|}{$\begin{array}{l}\text { Contabilistas Certificados } \\
\qquad(\mathrm{n}=392)\end{array}$} \\
\hline & & $X_{m}$ & $\mathbf{M}_{\mathbf{0}}$ & $\mathbf{M}_{\mathbf{d}}$ & $S$ & $X_{m}$ & $M_{0}$ & $\mathbf{M}_{\mathbf{d}}$ & $S$ \\
\hline Q22 & $\begin{array}{l}\text { Capacidade para aplicar o } \\
\text { conhecimento à prática }\end{array}$ & 5,25 & 6 & 5,00 & 1,05 & 5,68 & 6 & 6,00 & 1,16 \\
\hline Q23 & $\begin{array}{l}\text { Capacidade para organizar a } \\
\text { informação }\end{array}$ & 5,32 & 6 & 5,00 & 0,97 & 5,63 & 6 & 6,00 & 1,12 \\
\hline Q24 & $\begin{array}{l}\text { Capacidade para reportar a } \\
\text { informação }\end{array}$ & 5,22 & 6 & 5,00 & 1,00 & 5,63 & 6 & 6,00 & 1,17 \\
\hline Q25 & $\begin{array}{l}\text { Aplicar os requisitos éticos (princípios, } \\
\text { valores, atitudes) da profissão }\end{array}$ & 5,35 & 6 & 6,00 & 1,18 & 5,63 & 6 & 6,00 & 1,24 \\
\hline Q26 & $\begin{array}{l}\text { Compreender os contextos em que a } \\
\text { Contabilidade opera }\end{array}$ & 5,46 & 6 & 6,00 & 1,10 & 5,61 & 6 & 6,00 & 1,15 \\
\hline Q27 & $\begin{array}{l}\text { Compreender a linguagem técnica } \\
\text { contabilística }\end{array}$ & 5,86 & 6 & 6,00 & 1,03 & 5,97 & 7 & 6,00 & 1,11 \\
\hline Q28 & $\begin{array}{l}\text { Capacidade para preparar as } \\
\text { demonstrações financeiras }\end{array}$ & 5,53 & 6 & 6,00 & 1,18 & 5,90 & 7 & 6,00 & 1,17 \\
\hline Q29 & $\begin{array}{l}\text { Capacidade para efetuar uma análise } \\
\text { financeira }\end{array}$ & 5,11 & 6 & 5,00 & 1,30 & 5,67 & 6 & 6,00 & 1,28 \\
\hline Q30 & $\begin{array}{l}\text { Capacidade de estruturar um painel } \\
\text { de gestão com informação útil para a } \\
\text { tomada de decisão }\end{array}$ & 5,00 & 5 & 5,00 & 1,16 & 5,51 & 6 & 6,00 & 1,28 \\
\hline Q31 & Capacidade de planificar o trabalho & 5,01 & 5 & 5,00 & 1,21 & 5,30 & 6 & 5,00 & 1,36 \\
\hline \multirow[t]{2}{*}{ Q32 } & $\begin{array}{l}\text { Capacidade de cumprir com prazos e } \\
\text { regras }\end{array}$ & 4,79 & 5 & 5,00 & 1,21 & 5,26 & 6 & 5,00 & 1,42 \\
\hline & Valor médio & 5,26 & & & - & 5,62 & & & - \\
\hline
\end{tabular}

Legenda: $X_{m}$ - Média da amostra; $M_{o}-$ Moda; $M_{d}-$ Mediana; $S$ - Desvio-padrão.

A análise da Tabela 4 permite concluir que os estudantes finalistas demonstram, à semelhança das competências gerais, um grau de concordância baixo relativamente ao desenvolvimento das competências específicas ao longo do seu percurso de formação superior, uma vez que a média das respostas apresenta o valor de $\mathrm{x}_{\mathrm{m}}=5,26$ correspondente ao grau de "Concordo pouco" na escala de concordância utilizada. Esta análise é reforçada pela mediana, onde se verifica que, em 7 das 11 competências apresentadas, metade dos estudantes "Concorda pouco" com o seu desenvolvimento $\left(M_{d}=5,00\right)$. Por outro lado, 0 resultado mais comum para 8 das 11 competências específicas apresentadas foi de $M_{0}=6$, correspondente ao grau de "Concordo em grande parte". 
Os contabilistas certificados percecionam as competências específicas como importantes para o desempenho da sua atividade profissional, mas tal como as competências gerais, com graus de importância diferentes. A média das respostas indica o valor de $x_{m}=5,62$ correspondente ao grau de "Importante" na escala de importância utilizada.

A capacidade para efetuar uma análise financeira e a capacidade de cumprir com prazos e regras são as competências que apresentam o desvio padrão mais elevado para os estudantes finalistas e os contabilistas certificados, respetivamente.

Analisando a Tabela 4, verifica-se que, na perceção dos estudantes finalistas, as competências "compreender a linguagem técnica contabilística" e a "capacidade para preparar as demonstrações financeiras" são consideradas como as mais desenvolvidas, apresentando, respetivamente, a média aritmética de $x_{\mathrm{m}_{27}}=5,86$ e $\mathrm{x}_{\mathrm{m} 28}=5,53$. Contrariamente, consideram que as práticas utilizadas no percurso de formação superior frequentado não os prepara devidamente para desenvolver a "capacidade de estruturar um painel de gestão com

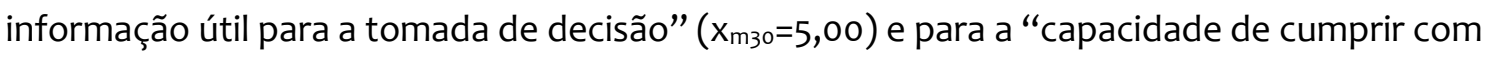
prazos e regras" $\left(x_{m_{32}}=4,79\right)$.

Arquero e Fernández-Polvillo (2019) concluíram que os estudantes optam por uma carreira em Contabilidade por causa das perspetivas de emprego. O esforço potencial do estudante em relação a determinado conteúdo estará intimamente ligado à perceção de utilidade, no sentido de aplicação prática posterior. Os autores argumentam que a ligação entre conteúdo e utilidade prática deve ser reforçada, especialmente em conteúdo teórico e em algumas capacidades não técnicas (comunicação, solução de problemas complexos e não estruturados, aplicação de julgamento profissional) às quais os estudantes atribuem pouca importância, pois não correspondem à sua visão das tarefas típicas da Contabilidade, mas que são essenciais tanto do ponto de vista profissional como em matéria de ensino superior.

A Tabela 4 evidencia, também, que na perceção dos contabilistas certificados, as competências específicas mais importantes para o desempenho da profissão são "compreender a linguagem técnica contabilística" $\left(x_{m_{27}}=5,97\right)$ e "capacidade para preparar as demonstrações financeiras" ( $\left.\mathrm{x}_{\mathrm{m} 28}=5,90\right)$. Por outro lado, a "capacidade de planificar o trabalho" e a "capacidade de cumprir com prazos e regras", assinalam os valores médios aritméticos mais baixos de, respetivamente, $x_{m_{31}}=5,30$ e $x_{m_{32}}=5,26$, o que revela que, tendencialmente, os contabilistas certificados consideram que estas competências não são tão importantes para o desempenho da profissão.

Estudos como os de Cory e Pruske (2012) referiam que muitos profissionais de Contabilidade expressaram insatisfação com o nível de conhecimentos e com as capacidades contabilísticas dos seus novos colaboradores. No entanto, quanto às competências técnicas, os resultados da presente investigação evidenciam que a maioria dos estudantes finalistas concordam que a compreensão da linguagem técnica contabilística é a competência mais desenvolvida ao longo do curso, assim como a maioria dos contabilistas certificados considera-a das mais importantes para o desempenho da profissão.

Face aos resultados obtidos, parece que, atualmente, todas as tarefas executadas ao longo do curso são suficientes para permitir aos estudantes o desenvolvimento dos conhecimentos técnicos da área científica da Contabilidade. Esta conclusão vai ao encontro do preconizado na NIE 3 do IAESB, a qual refere que as competências técnicas e funcionais 
da profissão são determinantes num plano curricular para a formação de um futuro contabilista.

\section{Conclusões}

Esta investigação pretendeu contribuir para o conhecimento das competências desenvolvidas nos cursos do ensino superior de Contabilidade. Foram analisadas as competências que os estudantes finalistas, inscritos no ano letivo 2013/2014, percecionam como desenvolvidas e comparadas com as que os contabilistas certificados consideram como importantes para o exercício da profissão. Procurou-se, assim, acrescentar evidência científica que poderá contribuir para ajudar as IES portuguesas a traçarem perfis curriculares que alinhem a formação superior de Contabilidade com as atuais necessidades das organizações.

Face aos resultados obtidos, conclui-se que os estudantes finalistas percecionam a "capacidade para trabalhar em equipa" como a competência geral mais desenvolvida, verificando-se que as práticas de ensino atuais são eficazes para incutir comportamentos orientados para a integração em equipas de trabalho, dinamizando-as através da participação ativa. Face à revisão da literatura efetuada, estes resultados poderão ter a ver com o aparecimento de novas metodologias de ensino como as práticas de simulação empresarial e os estágios curriculares. A possibilidade de o aluno ter uma primeira experiência no mundo laboral, mesmo antes de acabar o curso, permite que estes últimos ajudem no processo de aquisição de competências, sendo, assim, considerados como um mecanismo de aprendizagem e de inserção em contexto laboral.

Quanto aos contabilistas certificados, os resultados obtidos evidenciam que, para estes, é imprescindível saber fixar objetivos e metas, ter destreza para organizar as tarefas e atividades, realizando-as de forma metódica, uma vez que a competência geral "capacidade de organização", foi considerada das mais importantes para o exercício da profissão.

No que respeita às competências técnicas específicas da profissão, os resultados obtidos evidenciam que os cursos de Contabilidade contribuem para o processo de aquisição e compreensão dos conhecimentos técnicos contabilísticos, uma vez que os estudantes finalistas percecionam o "compreender a linguagem técnica contabilística" como a competência específica mais desenvolvida ao longo do seu percurso de formação superior. Esta competência é, também, apontada pelos contabilistas certificados como sendo das mais importantes para o exercício da atividade profissional.

É, assim, possível concluir que as novas metodologias de ensino-aprendizagem podem ser uma possível resposta aos novos objetivos do ensino superior, indo ao encontro dos desafios por este criado, contribuindo ativamente para a qualidade da formação dos estudantes, bem como a adequação dos perfis formativos às necessidades do mercado de trabalho (Almeida et al., 2009; Paisey \& Paisey, 2010; Almeida et al., 2015; Martins et al., 2016; Covas et al., 2017; Domingos et al. 2019).

Com o nível de exigência que é pretendido aos contabilistas certificados, no exercício das suas funções, atendendo aos atuais desafios e necessidades do mundo global, sugere-se às IES que reflitam sobre a convergência entre quais são as competências que pretendem 
que os seus estudantes obtenham durante a sua formação e aquelas que são consideradas como as mais importantes para o desempenho da profissão. Desta reflexão poderão surgir mudanças curriculares, para que os alunos adquiram todo o conhecimento e competências necessários para que a integração no mercado de trabalho e o desempenho da sua função decorram com sucesso.

Quanto às limitações da pesquisa, é de realçar a dificuldade sentida na obtenção das respostas aos inquéritos por parte dos estudantes finalistas. Esta condicionante poderá ter tido a ver com o facto de se ter optado por divulgar o inquérito online, não sendo possível aceder diretamente aos endereços eletrónicos dos alunos, o que levou ao pedido de divulgação do seu link, via email, aos responsáveis dos cursos.

Uma outra limitação deste estudo prende-se com o facto de a recolha de algumas respostas dos contabilistas certificados ter sido feita na acção de formação da OCC de Lisboa, tendo tido a vantagem de ser uma amostra acessível, fácil de inquirir e cooperante, mas que poderá ter provocado um possível enviesamento nos resultados, uma vez que esta amostra não pode ser considerada representativa de toda a população CC.

Num contexto de mudança no ensino superior, a investigação sobre o desenvolvimento de competências assume-se como um tema emergente e prioritário. Para futuras investigações, sugere-se um comparativo das conclusões obtidas neste estudo com a opinião das empresas que recrutam um maior número de diplomados em Contabilidade, como é o caso das Big Four, de forma a entender se ainda existe efetivamente um gap de expetativas entre a perceção dos estudantes e as expectativas das entidades empregadoras.

\section{Referências}

Almeida, R. (2004). Implementação do processo de Bolonha a nível nacional. Grupos por área de conhecimento - contabilidade. Parecer MCTES. Lisboa: MCTES. http://www.fap.pt/fotos/gca/Bolonha_Contabilidade.pdf

Almeida, R., Dias, A. \& Pinheiro, P. (2009). A utilização de novas tecnologias: O modelo de simulação empresarial no ensino da Contabilidade. Comunicação apresentada no XV Congresso da AECA: Novos caminhos para a Europa: o papel das empresas e governos. Disponível em http://www.aeca1.org/pub/on_line/comunicaciones_xvcongresoaeca/cd/133g.pdf

Almeida, R., Morgado, J., Silva, J. L., Domingos, R., Santos, A., Marques, A., Conceição, C. \& Nogueira, R. (2015). O Projeto em Simulação Empresarial como método de ensino sucesso: A perspetiva dos alunos de contabilidade do ISCAL. Atas do V Congresso dos TOC. Disponível em https://www.occ.pt/news/trabalhoscongv/pdf/49.pdf

Arquero, J. \& Fernández-Polvillo, C. (2019). Estereotipos contables. Motivaciones y percepciones sobre la contabilidad de los estudiantes universitarios de Administración de Empresas y Finanzas y Contabilidad. Spanish Accounting Review, 22(1), 88-99. doi: 10.6018/rcsar.22.1.354341

Aryanti, C. \& Adhariani, D. (2020). Students' perceptions and expectation gap on the skills and knowledge of accounting graduates. Journal of Asian Finance, Economics and Business, 7(9), 649-657. doi: 10.13106/jafeb.2020.vol7.nog.649

Bolívar, A. (2007). La planificación por competencias en la reforma de Bolonia de la educación superior: Un análisis crítico. Educação Temática Digital, 9, n. ${ }^{\circ}$ especial, 68-94. doi: 10.20396/etd.vgin.esp..728 
Bui, B. \& Porter, B. (2010). The expectation-performance gap in accounting education: An exploratory study. Accounting Education, 19(1-2), 23-50. doi: 10.1080/09639280902875556

Cabral-Cardoso, C., Estevão, C. \& Silva, P. (2006). Competências transversais dos diplomados do ensino superior: Perspectiva dos empregadores e diplomados. Guimarães: TecMinho.

Ceitil, M. (2016). Gestão e desenvolvimento de competências. Lisboa: Edições Sílabo.

Cory, S. \& Pruske, K. (2012). Necessary skills for accounting graduates: An exploratory study to determine what the profession wants. Proceeding of ASBBS Annual Conference: Las Vegas, 19(1), 208-218.

Covas. A., Soares, V. \& Pimentel, P. (2017). O estágio curricular e a simulação empresarial como ferramentas para o desenvolvimento de competências. XVI Congresso Internacional de Contabilidade e Auditoria (CICA) - da Academia à profissão. Aveiro, Portugal. Disponível em https://www.occ.pt/dtrab/trabalhos/xviicica//finais_site/229.pdf

Domingos, A., Sarmento, M. \& Duarte, M. (2019). Student and employer perceptions of accounting skills development. In O. Gomes \& M. Gubareva (Eds.), Contributions on applied business research and simulation studies (pp.63-88). Nova lorque: Nova Science Publishers.

Estatuto da Ordem dos Contabilistas Certificados. (2015). Lei nº.139/2015, de 7 de setembro. Diário da República nº. 174/2015 - I Série. Lisboa: Assembleia da República.

Evans, J. \& Mathur, A. (2005). The value of online surveys. Internet Research, 15(2), 195-219. doi: $10.1108 / 10662240510590360$

Hassall, T., Joyce, J., Montaño, J. L. A. \& Anes, J. (2005). Priorities for the development of vocational skills in management accountants: A European perspective. Accounting Forum, 29(4), 379394. doi: 10.1016/j.accfor.2005.03.002

International Accounting Education Standards Board (IAESB). (2015). IES 3 - Professional skills and general education. Disponível em https://www.ifac.org/sites/default/files/publications/files/ies-3-professional-skills-1.pdf

International Federation of Accountants [IFA]. (2017). Handbook of international education pronouncements. 2015 edition. Nova lorque: IFAC.

International Federation of Accountants. (2005). The roles and domain of the professional accountant in business. Disponível em http://www.apesb.org.au/download.php?codeP=384.

Jackling, B. \& De Lange, P. (2009). Do accounting graduates' skills meet the expectations of employers? A matter of convergence or divergence. Accounting Education: An International Journal, 18(4-5), 369-385. doi: 10.1080/09639280902719341

Jones, A. (2010). Generic attributes in accounting: The significance of the disciplinary context. Accounting Education, 19(1), 5-21. doi: 10.1080/09639280902875523

Kavanagh, M. \& Drennan, L. (2008). What skills and attributes does an accounting graduate need? Evidence from student perceptions and employer expectations. Accounting \& Finance, 48(2), 279-300. doi: 10.1111/j.1467-629x.2007.00245.x

Lei nº. 139/2015, de 7 de setembro. Diário da República nº. 174/2015 - I Série. Lisboa: Assembleia da República.

Martins, D., Espejo, M. M. \& Frezatti, F. (2016). Problem-based learning no ensino de contabilidade gerencial: Relato de uma experiência brasileira. Revista de Educação e Pesquisa em Contabilidade (REPeC), 9(4). doi: 10.17524/repec.vgi4.1340

Neves, J. G., Garrido, M. \& Simões, E. (2015). Manual de competências pessoais, interpessoais e instrumentais: Teoria e prática. Lisboa: Edições Sílabo. 
Paisey, C. \& Paisey, N. J. (2010). Developing skills via work placements in accounting: Student and employer views. Accounting Forum, 34, 89-108. doi: 10.1016/j.accfor.2009.06.001

Pan, P. \& Perera, H. (2012). Market relevance of university accounting programs: Evidence from Australia. Accounting Forum, 36, 91-108. doi: 10.1016/j.accfor.2011.11.001

Rouco, J. \& Sarmento, M. (2012). Diferentes abordagens sobre o conceito de competência. Proelium Revista Científica da Academia Militar, Série VII (2), 7-29.

Van der Klink, M., Boon, J. \& Schlusmans, K. (2007). Competências e ensino superior profissional: Presente e futuro. Revista Europeia de Formação Profissional, 40(1), 72-89.

AleXANDRA Domingos licenciou-se em Contabilidade e Administração - ramo de Controlo Financeiro no ISCAL, onde concluiu, em 2010, o mestrado em Contabilidade. Em 2017, doutorou-se em Gestão na Universidade Lusíada de Lisboa com a apresentação de uma tese sobre as competências gerais e específicas desenvolvidas nos cursos de contabilidade do $10^{\circ}$ ciclo do ensino superior em Portugal. Desde 2004, tem lecionado diversas unidades curriculares de Contabilidade Financeira, Contabilidade de Gestão e de Planeamento e Controlo Financeiro no ISCAL, onde atualmente desempenha as funções de professora ajunta. Atualmente, é subdiretora do Mestrado em Contabilidade do ISCAL. É autora de artigos técnicos e científicos na área da Contabilidade, sendo as suas áreas de investigação o ensino da Contabilidade e a Contabilidade de Gestão. Endereço institucional: Avenida Miguel Bombarda, n 20, 1069-035 Lisboa. ORCID: 0000-0002-5521-8221.

MANUela SARMento é professora de Gestão na Universidade Lusíada (ULL). É investigadora integrada do CEPESE (UP) e investigadora convidada do COMEGI (ULL). Possui a agregação em Gestão pela UBI, o doutoramento em Gestão pelo IST-UL, o mestrado em Ciências da Gestão pelo ISCTE-IUL. Orientou 16 teses de doutorado e 153 dissertações de mestrado, publicou 197 artigos internacionais e 154 artigos nacionais com arbitragem científica e 13 livros. Foi Presidente do Centro de Pesquisa CINAMIL da Academia Militar e do CITIS (ULL). Foi avaliadora de novos cursos de graduação e mestrado no Ministério do Ensino Superior e avaliadora de projetos de P\&D na UE e na Agência de Credenciamento Italiana e Grega. Foi Presidente da Associação Portuguesa de Gestão e Vice-Presidente da Associação Nacional de Auditores de Defesa. Endereço institucional: R. Junqueira 188, 1349-001 Lisboa, Portugal. ORCID: 0002-8658-3416.

MANUELA DUARTE é licenciada pelo ISEG em Finanças com 14 valores, mestre em Gestão e Inovação Tecnológica pelo IST com 15 valores e doutorada em Gestão: Contabilidade pela Universidade Lusíada com 18 valores e louvor. Publicou 4 livros, vários manuais de apoio e cerca de 150 artigos e capítulos de livros com arbitragem científica. É professora coordenadora do ISCAL e associada da Universidade Lusíada. Endereço institucional: Avenida Miguel Bombarda, n²0, 1069-035 Lisboa.

Submetido em 4 de novembro de 2020

Aceite em 19 de fevereiro de 2021 